\title{
Reporting Information as a Form of Communication of Business Entities
}

\author{
Tatyana Rudakova ${ }^{1,2, *}$ Marina Semikolenova ${ }^{1}$ Svetlana Zemlyakova ${ }^{3}$
}

\author{
${ }^{1}$ Altai State University, Lenin Ave 61, G. Barnaul 656099 Russia \\ ${ }^{2}$ Altai state technical university I.I. Polzunova, Lenin Ave 46, G. Barnaul 656038 Russia \\ ${ }^{3}$ Don State Agrarian University, Michurina st. D.1a, G. Persianovsky, Rostov Region, 346493, Russia \\ *Corresponding author.Email: rta_62@mail.ru
}

\begin{abstract}
The increasing trend in the role of the Internet indicates that it is virtual space that provides most of the information flows required in the process of institutional unit interaction. The subject of the study is the reporting information of economic entities as a form of communication, including through information and communication technologies. The purpose of the article is to analyze the impact of changes in the economy and society, under the influence of both foreign economic trends and internal transformations, on the content of the information source and presentation format. The study is based on the principles of a systematic approach using methods of a popular scientific and, private scientific nature, comparative analysis and methods of logic. The article considers the prerequisites for the formation of new requirements to the content of the information field, ensuring the receipt by economic entities of the data of interest on counterparties and business partners; The impact of modern changes in the organization of information exchange of institutional units is identified as a stage of evolutionary views on the possibilities of transmitting information in matters of theory and improving the technical base of the information process. It is argued to change the content of reporting information in the era of the "economy of trust" and to prepare personalized reporting as a result of evolutionary transformations of the basic source, improvement of technical conditions, ensuring a certain equalization of opportunities of communication participants and formation of social capital of the company. The results of the study concluded that the capabilities of artificial intelligence should be used in the collection and processing of information, and the preparation of accounts for accounting, financial, corporate, integrated and personalized, much less the interpretation of its content, remains the responsibility of a specialist in this field of knowledge.
\end{abstract}

Keywords: information, accounting (financial) reporting, information technology, digital transformation of

the economy, trust economy, personalized reporting

\section{INTRODUCTION}

Institutional units, in the face of changing economic systems influenced by globalization, increasing competition, a changing external environment and the increasing role of the Internet in ensuring the interaction of participants in economic space, have a high level of dependence on the information on which they rely in the course of their activities. The increasing trend in the role of the Internet indicates that it is virtual space that provides most of the information flows required in the process of institutional unit interaction. According to a number of researchers, the globalization of the economy is one of the main reasons for the emergence of the process of virtualization of information exchange among participants in the economic relations of modern society.
A few years ago it was possible to say that communication in virtual space is typical for enterprises with an adhocratic management structure. Today, it is one of the mandatory conditions of communication of the modern economic entity with the participants of the economic space.

\subsection{Related Work}

Detailed analysis and genesis of approaches to the definition of the term "adhocracy" is presented in the article by T. S. Krasnikova "Adhocratic Organization: Genesis of Concepts and Basic Representations" [1]. The emergence of the term "adhocracy" is attributed to Warren Bennis 's research into leadership problems [2]. The idea of the author, who defines adhocracy as a concept opposite hierarchy, centralized control and bureaucratic organization, supports Alvin Toffler in his works. "Adhocracy is the power of intellectuals mobilized on a 
particular occasion" [3, C.3; 4, Page. 215]. The concept of adhocratic organization is beginning to be actively used by researchers in the field of management [5.6-10]. G. Minzbergum gives a detailed and comprehensive description of the term, emphasizing the project component of the participants "activities, proportional inequality of specialists, absence of stereotypes of thinking and presence of creative approach in the behavior of employees in the process of performance of functional duties [5].

The emergence of such a structure of economic management of complex economic formation determines the environment in which it functions. Current economic trends suggest the need to use this tool in a complex environment management system, where it is necessary to combine into organic multidisciplinary teams to generate new knowledge and skills.

A characteristic feature of the environment of modern economic units is the dynamism and complexity of forecasting, in which the behavior of economic entities is stimulated by competition. Professional "communication" is provided through information and communication technologies, and the main resource is information.

The nature, essence and content of the term "information" have changed over time, as evidenced by a significant number of publications [11,12-16]. According to the philosophical concept, information is one of the properties of matter and the basic concepts of formalized reflection of objective reality. At this stage of development of economic relations information can be considered on the one hand as a resource having its individual value characteristic and can be used in the process of creation of new value, on the other hand - as a commodity, i.e., a final product of activity of an economic entity. Changing the role and significance of information today allows researchers to call modern society informational.

\subsection{Our Contribution}

Accounting (financial) statements as a state information resource

Accounting (financial) statements, as a state information resource, have gone a long way in their development both in terms of content and in terms of presentation format to interested users. Evolutionary changes in reporting information were dictated by the development of economic relations, resulting in changes in the information interests of the entities to which it was intended.

Modern changes in the sphere of information exchange of institutional units can be considered, on the one hand, as another stage of evolutionary views on the possibilities of transmitting information in matters of theory, on the other - as improvement of the technical base of the information process.

The intensive digital transformation of the economic processes of modern society at this stage does not show a significant impact on the basic information resource accounting (financial) statements, which are mandatory for submission by economic entities, neither in meaningful terms, nor in format, nor in terms of transmission to interested users.

The problem of collecting and generalizing primary information has been solved centuries ago. "The Language of Description of the Facts of Economic Life" [17, c.5] in his book "The Tract on Accounts and Records" presented Franciscan monk Luca Pacholi (1445-1517). "He did the most important thing that was needed to develop the business" [17, c.5]. For this he was included by the German philosopher and cultural scientist O. Spengler (1880-1936) in the cohort of great people who changed the world. According to the philosopher, "any fact, even the simplest, already contains history" [18]. It is the historical nature of financial reports that at the present stage becomes the subject of criticism of reporting information by management. However, this aspect makes it possible to carry out analytical procedures and extrapolate the situation in the economic life of the subject into conditions and periods of interest to the user, with adjustment for predicted changes in the external environment and assessment of such impact on the business.

The desire of the participants of the economic space, actively seeking mutually beneficial conditions and forms of cooperation, under the influence of market mechanisms and constant change of "sentiment" of an international nature, justifies negative attitude to financial reporting, which does not correspond to information expectations. As a result, we see evolutionary transformations of the information source almost on a permanent basis, as confirmed by colabs not only at the terminological level, but also at the legislative level. At a time when the law on accounting contains the definition of "accounting (financial) statements," the established scientific practice of this concept attempts to adjust depending on the size of invested capital, the scale of business, the structure and system of management, the information expectations of users. It explains use in scientific research and publications of practical orientation of terms accounting reports, financial statements, the consolidated reporting, the corporate reporting, the integrated reporting. The name of the information source indicates the amount of information it contains, the scope of the reporting organization 's activities and the form of business management. The Law on Accounting, which applies to all economic entities, does not rely on these parameters, and such classification of the information source is not provided in the document. The development of reporting as an information source reflects a direct link with the needs of users of each period of historical development of the country. The modern stage is characterized by the transition to international financial reporting standards, and the investor has been declared a priority user, as it is it that sets the tone of the content of the source. Decisive action on equity requires information to convince the owner of the validity of the decisions taken. And today such a role is assigned to corporate, integrated reporting, report on sustainable development of the company. This is a set of additional and accompanying information to the financial data block that characterizes the company as an object of investment. It should be noted that the amount of this data is quite 
large to assert the useful properties of the information. Since, first, the period during which it is summarized indicates a historical character; Second, any planning figures, such as those that describe an organization 's ability to generate value in the short, medium and long term, are forecast and may differ from actual values; Third, the principle of a rational approach to the organization and maintenance of accounting in the enterprise is questioned, given the difficulty in preparing the report. As a result, there has been an increase in analytical information, at least for integrated reporting. Let us turn to historical facts indicating that it is the trend of increasing analytic balance that characterizes the fourth stage of reporting development (1946-1960,). The number of indicators of the approved balance sheet form almost doubled between 1941 and 1953 from 250 to 415, making it necessary to adjust the content of the report.

\section{BACKGROUND}

\subsection{The Economy of Trust and Financial Reporting}

The development of modern technologies not only provides access to information about the activities of the economic entity, but also expands the possibilities of interfirm communication. It is about preparing personalized reporting for counterparties who have gained trust in the business [19]. As M.L. Pyatov notes, "trust is certainly not something new in economic life. Any business is a business based on trust "[20]. According to F. Dickhoner, the development of society takes place under the influence of an innovative factor, in turn, the adoption and dissemination of innovation is based on trust, which is a key factor in the development of social relations [19]. Monopolization of business is nothing more than the trust of consumers of goods and public goods produced by corporate entities. It is the trust of the society that ensures the positive dynamics of sale of products and the increase in the cost of capital of the company.

The development of information technologies makes it possible to decentralize the information exchange between the participants of the economic space and to create new terms characterizing the "message" to the users of the reporting organization. Today, the production of personalized information is being disseminated, the content of which is determined by the priority user thanks to the possibilities of developing technologies of data collection, storage and transfer. In many ways, this trend is inevitable in the context of providing a large amount of information about the activities of economic entities, which requires considerable resources for the user to read and interpret it. In this case, the presentation format for visual perception and analysis of information becomes unimportant if its viewing volume is 120 to 400 pages. In turn, client-requested reporting generated by the reporting organization significantly reduces the period from receipt to use in management decision-making. In this case, the information retains a number of qualitative characteristics that it is intended to have - the timeliness of obtaining the information, the materiality of the information, and therefore its usefulness.

Creating personalized or "on-order" reporting will resolve the conflict between the priority user and the reporting organization, as it meets the customer 's information expectations and increases the company 's investment expectations.

The capabilities of such communication in the information field are provided by the existing technical conditions. The issue of full or limited access to the information of interest about the activity of the enterprise may be the subject of a contract between business partners.

Obtaining a unified set of reporting information to the user guarantees the existing and regulatory obligation of the economic entity to provide it to external users. According to the expert in the field of innovation, digital transformation of the economy Philip Dickhoner, the expansion of the possibility of the information field to influence the state of business, determines decentralization of the activities of market space participants [19]. The mechanism of interaction between economic actors is information technologies, which ensure a certain equalization of opportunities of participants and formation of social capital of the company. In a situation where the opportunities of market participants are equalized, social capital formed by trust in the company 's actions begins to play a fundamentally new role in choosing it as a business partner. The success of the business today is the result of the gained trust among partners and the society of consumers of the benefits created by the company. For this reason, F. Dickhoner calls trust the engine of the digital economy.

Traditionally, the institution of auditing has provided a certain level of trust in the information source of an individual company to interested users for a long time. The main guarantor of trust in this case was the opinion of a specialist confirming the validity of the information presented in the accounts on the state of the company 's assets and the results of effective or ineffective management.

Today we see a gradual transfer of the functions of the guarantor, confirming the reliability of the information source for the participants of economic relations, from the specialist of this branch of knowledge of information and communication technologies. It cannot be said that this is a direct transfer of powers, as the restriction is the social capital of the company, formed as a result of the trust of the society.

The Institute of Trust, together with increasing technological capabilities in the process of collecting, storing and transmitting information, expands the boundaries of inter-firm communication, ensures decentralization and self-regulation of economic relations of economic entities. The independence of the interacting companies leads to establishment of formats of information exchange by means of preparation of the personified reports, reports "by request" by priority users. 
Users of reporting information who are not in the category of priorities for the reporting organization are certainly not deprived of the right to receive information in the format established by professional communities or regulatory bodies. On a continuous basis, amendments are made to the regulations governing the content of accounting (financial) statements, which indicates a desire to ensure compliance with the rules and norms of the existing regulators with the changes taking place in the country. In the context of the digital transformation of the economy, accounting (financial) statements receive the status of a state information resource, access to which is determined by the regulatory body. In terms of maintaining confidence in the information contained in the accounts in the header part of the balance sheet, the reporting organization will disclose information about the audit organization or individual auditor sharing the information risk with users, the taxpayer identification number and the main, state registration number.

\subsection{Artificial intelligence and financial reporting}

The modern era, characterized by the introduction of artificial intelligence into the life of society, the constant growth of the information field in which economic actors operate and the complication of its configuration, contrary to the erroneous opinion about the loss of relevance of the profession of accountant, on the contrary, strengthens its role as a specialist interpreter of the information flow in the form of accounting (financial) reporting of any content, volume and complexity. As Keynes noted, such fears are the result of emerging difficulties during the transition to a new economic period, when technological growth exacerbates the problem of employment. [21] In this situation, it is necessary to agree with the opinion of Ayesha Khanna, an artificial intelligence specialist, expressed in a report at the 2018 World Congress of Accountants in Sydney (WCOA 2018), the content of which presented in his article M.P. Pyatov that the main purpose of the use of artificial intelligence in any sphere of social life is to strengthen human capabilities [22]. Artificial intelligence capabilities should be used in the process of collecting and processing information that does not require interpretation of its content and significantly facilitates accounting works, such as processing of primary documents, classification of information. However, the development of messages for users who are focused on gaining trust in the business and attracting investments remains the responsibility of a specialist in the field of knowledge.

\section{CONCLUSION}

In summary, the evolution of accounting (financial) statements continues. The changes taking place, under the influence of information and telecommunication technologies, the introduction of artificial intelligence into the life of society, indicate the arrival of a new stage in its development - the economy of trust, and the list of terms characterizing it is supplemented by the phrase "personalized financial reporting".

\section{REFERENCES}

[1] T. S. Krasnikova, Adhocratic organization: the genesis of concepts and basic concepts, Bulletin of St. Petersburg State University. Ser. 8. 2003, Vol. 4, no. 32, pp 71-85

[2] G Warren, Bennis and Philip E. Slater, The Temporary Society, New York, 1968, 148 p.

[3] A Toffler, Powershift: Knowledge, Wealth, and Violence at the Edge of 21st Century, Bantam Books, 1990, p.3.

[4] E. Toffler, Third Wave Moscow, 1992.

[5] G. Mintsberg, Structure in the Fist: Creating an Effective Organization, St. Petersburg, 2001.

6] Cameron K., Quinn R. Diagnostics and change in organizational culture, Translation from English edited by I. V. Andreeva, St. Petersburg, 2001.

[7] G. Mintsberg, D. Quinn, S. Goshal, Strategic Process, St. Petersburg, 2001.

[8] R.Deshpand, J.Farley, Corporate Culture Customer Orientation, and Innovativeness in Japanese Firms: A Quadrad Analysis, Journal of Marketing, 1993, Vol. 57, no 1, pp. 23-38.

[9] M.Alvesson, Leadership as Social Integrative Action. A Study of a Computer Consultancy Company, European Group for Organizational Studies Organization Studies, 1992, Vol. 13, no 2, pp. 185-209.

[10] A.McHugh, H.Mintzberg, Strategy Formation in an Adhocracy, Administrative Science Quarterly, 1985. pp. 160-197.

[11] E. A. Petrichenko, Information and philosophical categories "phenomenon and essence", Modern problems of science and education, 2014, no. 1

[12] V.Khurgin, On the definition of the concept of "information", Information Resources of Russia, 2007, no. 3 . 
perspectives, translation from German and notes by I. I.

[13] A. D. Ursul, The Nature of Information, Moscow, Politizdat, 1968, 288 p.

[14] D. Glick, Information. History. Theory. Stream, Moscow, $576 \mathrm{p}$

[15] R. L. Stratonovich, Information Theory, Moscow, Soviet Radio, 1975, 424 p.

[16] I. V. Melik-Gaykazyan, Information Processes and Reality, Moscow, Science, Fizmatlit, 1997, 192 p.

[17] L. Pacioli, Treatise on Accounts and Records Edited by Ya.V. Sokolova, Moscow: Finance and Statistics, 2001, 368 p.

[18] O. Spengler, Sunset of Europe, Essays on the morphology of world history. 2. World historical
Makhankov, Moscow: Thought, 1998, 606 p.

[19] F.K. Dichoner, Trust Economics: Building Strong Networks and Implementation, Singapore: Marshall Cavendish Business, 2017.

[20] M.L. Pyatov, Philip Dickhoner: Accounting and the Economy of Trust, 1C: Accounting, 2019

[21] J. M. Keynes, Economic Opportunities of Our Grandchildren, Economic Issues, 2009, No. 6, pp. 6067.

[22] M.L. Pyatov, Ayesha Hannah: "Do accountants need to be afraid of artificial intelligence?", 1C:

Accounting. 